\title{
Evaluation of the integrity of the deltoid ligament in supination external rotation ankle fractures: a systematic review of the literature
}

\author{
Michel P. J. van den Bekerom • \\ Eduard L. A. R. Mutsaerts · C. Niek van Dijk
}

Received: 13 February 2008 / Published online: 25 October 2008

(C) The Author(s) 2008. This article is published with open access at Springerlink.com

\begin{abstract}
Background and purpose Review the literature concerning modalities to evaluate the integrity of the deltoid ligament in patients with supination external rotation ankle fractures.

Methods The electronic databases Pubmed/Medline, CINAHL and Embase were searched from 1987 to November 2007 to identify all published original studies concerning diagnostic modalities to evaluate the integrity of the deltoid ligament in adult ankle fractures.

Results This review included nine studies involving 423 ankle fractures. Three trails investigated medial tenderness; two studies, ecchymosis; two studies, swelling; one study, an injury radiograph; six studies, a type of radiographic stress view; one study, the Lauge-Hansen classification; one study, MRI; and one article studied arthroscopy in the evaluation of the deltoid ligament integrity.

Interpretation Swelling, ecchymosis, medial tenderness, initial injury radiographs and the Lauge-Hansen classification are less adequate predictors of the integrity of the deltoid ligament. Manual or the less painful variant, the gravity external rotation stress radiographs are considered the gold standard. The amount of medial clear space widening indicative of a positive external rotation stress test has been somewhat variable in the literature but $\geq 5 \mathrm{~mm}$ is generally regarded as most reliable. Achieving adequate external rotation of the foot when obtaining stress radiographs is more important than positioning the ankle in the appropri-
\end{abstract}

M. P. J. van den Bekerom $(\bowtie) \cdot$ E. L. A. R. Mutsaerts .

C. N. van Dijk

Department of Orthopaedic Surgery,

Academic Medical Centre/University of Amsterdam, P.O. Box 22660, 1100 DD Amsterdam, The Netherlands e-mail: Bekerom@gmail.com ate degree of ankle flexion. The amount of applied force necessary when performing an external rotation stress radiograph is not well defined and mainly determined by the patient's pain level. The indication for surgery should not be based on the absolute value of one parameter but on the combination of several parameters. If nonoperative treatment is chosen despite a positive stress radiograph, close follow-up is critical because subluxation of the ankle joint is still possible. MRI could be useful in individual cases.

Keywords Ankle fracture $\cdot$ Deltoid ligament $\cdot$ Diagnosis · Tenderness $\cdot$ Swelling $\cdot$ Ecchymosis $\cdot$ Stress radiographs

\section{Introduction}

Previously, surgeons stated that reduction of the lateral malleolus was the key element in treating ankle fractures [56]. Today it is recognized that the deep deltoid ligament is the primary stabilizer of the ankle and prevents lateral talar shift and external rotation of the talus. The deep deltoid ligament originates on the posterior border of the anterior colliculus, the intercollicular groove, and posterior colliculus of the tibia and it is oriented transversely and inserts into the entire nonarticular surface of the medial talus. A rupture of the deep deltoid ligament results in ankle instability after distal fibular fracture $[19,21,30,31,37,42$, $43,52]$. The stability of the loaded ankle is primarily due to the deltoid ligament, which exerts a restraining influence on the external rotation of the talus [31]. Michelson et al. [30, 31] showed in a cadaver model that an osteotomized lateral malleolus and a transected superficial deltoid ligament did not allow for widening of the medial clear space and talar translation. However, when the deep deltoid ligament was 
transected, the ankle became unstable. Ankle fractures that allow for talar subluxation are considered to be unstable.

Lauge-Hansen supination external rotation (SER)-type ankle fractures are equivalent to a Weber B injury and account for $40-75 \%$ of all ankle fractures [13, 20, 23, 26, $30,33,58]$. The SER-type fractures are numbered I through IV in order of severity [8]. A SER II injury is an isolated lateral malleolus fracture with an intact medial ligamentous complex and is amenable to nonoperative treatment $[3,7,9$, 21, 25, 27, 40, 41, 54, 58]. A SER IV injury consists of a lateral malleolar fracture with a deep deltoid ligament disruption, a medial malleolar fracture, or both. Operative fixation of the fibular fracture is usually required in SER IV ankle fractures $[4,13,19,21,37,52,54,58]$. In the case of a medial malleolar fracture associated with deltoid ligament injury, fixation of the medial malleolus may not restore ankle joint stability and an internal fixation of fibular fracture may be necessary [6, 48, 49, 52]. Evaluation of the integrity of the deep deltoid ligament is particularly important when patients present with an isolated not dislocated fibular fracture and a radiographically normal medial clear space [12].

Until today we used the clinical signs such as ecchymosis, swelling, and tenderness to evaluate integrity of the medial structures. Recent studies showed that these signs are not reliable $[12,16,29]$ and we are of the opinion that the stress radiographs are more reliable. Today there is no clear review, and there is no evidence-based flow chart as to how to evaluate deltoid ligament integrity. Therefore, the literature was reviewed according to the MOOSE guidelines $[50,51]$ to evaluate the value of physical examination, radiological investigations, arthroscopy, or fracture classifications in assessing deltoid ligament integrity in SER ankle fractures. The second objective of this article was to formulate recommendations for clinical practice and future research.

\section{Methods}

Clinical and cadaveric studies that included diagnostic modalities to identify a deltoid ligament rupture in adult humans with an ankle fracture were eligible for this systematic review. Abstracts from scientific meetings were excluded. Papers outside the English language were considered if translation was possible.

We searched MEDLINE with PubMed, CINAHL, EMBASE and reference list of the included articles from 1987 to November 2007. In MEDLINE (PubMed), we used clinical queries feature with a broad search for: (diagnosis OR diagnosing OR diagnostic) AND [(medial AND (ligament* OR ligamentous)] OR medial clear space* OR deltoid ligament* OR medial injury) AND (ankle fracture* OR fibular fracture* OR lateral malleolus fracture*). The search in the other databases yielded no additional relevant articles. The result was combined with an electronically backward search and checked manually for related articles. Furthermore, the lists of references of retrieved publications were manually checked for additional studies potentially meeting the inclusion criteria and not found by the electronic search.

From the title, abstract, two reviewers (MB, EM) independently reviewed the literature searches to identify relevant articles for full review. From the full text, using the above mentioned criteria; two reviewers (MB, EM) independently selected articles for inclusion in this review. Disagreement was resolved by consensus or by third party adjudication (CD).

It was the initial intention of the authors to use a strict methodology for paper selection, focusing on different testing modalities, comparison with a golden standard and a separate evaluation of the testing modalities in different fracture types. These scientific standards had to be abandoned however, as almost none of the available papers fulfilled the above mentioned criteria; the only real golden standard is to make a surgical incision over the deltoid ligament and inspecting its integrity in all included ankle fractures. Comparison between different tests was not possible since there was no uniformity between reports in different type of ankle fractures, associated soft-tissue injury, diagnostic criteria, testing procedures and golden standard. Sensitivity, specificity, negative predictive value, positive predictive value and comparisons between SER II and SER IV ankle fractures (with $P$ value) were extracted from the included studies.

\section{Results}

The above defined search strategy resulted in 364 potentially eligible articles. Independent review of the titles, abstract and the full text resulted in the inclusion of nine articles. The main reason for exclusion was that the diagnosis of interest was not a deltoid ligament rupture/insufficiency. The nine included studies involved 423 ankles with an (simulated) (cadaveric) ankle fracture. An overview is shown in Tables 1 and 2. Three trails investigated medial tenderness [12, 16, 29]; two studies, ecchymosis [16, 29]; two studies, swelling [16, 29]; one study, an injury radiograph [46]; six studies, a type of radiographic stress view $[12,16,18,29,32,35,45]$; one study, the Lauge-Hansen classification [46]; one study, MRI [24]; and one article studied arthroscopy [46] in the evaluation of the deltoid ligament integrity. The publication dates span 6 years; in 2001, Michelson et al. [32] was the earliest and in 2007, Koval et al. [24] and Schock et al. [45] were the most recent publications. All studies were performed in the US. 
Table 1 Included studies

\begin{tabular}{|c|c|c|c|}
\hline Study & Country/year & Patients & Comparison \\
\hline DeAngelis et al. [12] & US/2007 & $\begin{array}{l}\text { 55; Weber B with normal medial clear space, } \\
\text { age } 42 \text {, M 26, F } 29\end{array}$ & $\begin{array}{l}\text { Medial tenderness versus external } \\
\text { rotation stress views }\end{array}$ \\
\hline Park et al. [35] & US/2006 & $\begin{array}{l}\text { 6; cadaveric ankles destabilised according } \\
\text { to Lauge-Hansen SER mechanism, } \\
\text { age } 49-72, \text { M } 3, \text { F } 3\end{array}$ & $\begin{array}{l}\text { Positioning in neutral flexion, } \\
\text { dorsiflexion, and plantarflexion, } \\
\text { and the application of internal } \\
\text { and external rotational forces }\end{array}$ \\
\hline McConnell et al. [29] & US/2004 & $\begin{array}{l}\text { 138; Weber B SER fibula fractures (exorotation } \\
\text { in neutral flexion), age NM, M NM, F NM }\end{array}$ & $\begin{array}{l}\text { Medial tenderness, swelling } \\
\text { and ecchymosis versus stress } \\
\text { radiographs }\end{array}$ \\
\hline Gill et al. [18] & US/2007 & 25; 12 SER II and 13 SER IV, age 37, M 12, F 13 & $\begin{array}{l}\text { Manual-stress versus gravity-stress } \\
\text { radiographs (exorotation } \\
\text { in neutral flexion) }\end{array}$ \\
\hline Egol et al. [16] & US/2004 & $\begin{array}{l}\text { 101; SER with intact mortise } 35 \text { SER II } \\
\text { and } 66 \text { SER IV, age 40, M 44, F } 57\end{array}$ & $\begin{array}{l}\text { Medial tenderness, swelling, } \\
\text { and ecchymosis versus stress } \\
\text { radiographs (exorotation in dorsal flexion) }\end{array}$ \\
\hline Michelson et al. [32] & US/2001 & 8; cadaveric ankles, age NM, M NM, F NM & $\begin{array}{l}\text { Intact ankle, distal fibular oblique osteotomy, } \\
\text { plated fibula after osteotomy, transection } \\
\text { of the superficial deltoid with fibula } \\
\text { osteotomized or plated, and all possible } \\
\text { combinations of deep deltoid transection } \\
\text { with previous combinations }\end{array}$ \\
\hline Schuberth et al. [46] & US/2004 & $\begin{array}{l}\text { 40; displaced lateral malleolar fractures ORIF, } \\
\text { age } 44, \text { M 26, F } 14\end{array}$ & $\begin{array}{l}\text { Medial clear space on injury radiographs } \\
\text { and Lauge-Hansen versus arthroscopy }\end{array}$ \\
\hline Koval et al. [24] & US/2007 & $\begin{array}{l}\text { 21; lateral malleolar fractures with positive } \\
\text { stress test, age } 39 \text {, M 12, F } 9\end{array}$ & $\begin{array}{l}\text { Medial clear space on manual (exorotation) } \\
\text { stress radiograph versus MRI }\end{array}$ \\
\hline Schock et al. [45] & US/2007 & 29; SER fibula fractures, age 42, M 17, F 12 & $\begin{array}{l}\text { Manual-stress versus gravity-stress } \\
\text { radiographs (exorotation in neutral } \\
\text { dorsal flexion) }\end{array}$ \\
\hline
\end{tabular}

$N M$ not mentioned

Table 2 Conclusions of included studies

\begin{tabular}{ll}
\hline Study & Conclusion \\
\hline DeAngelis et al. [12] & No correlation of medial tenderness with positive stress radiographs \\
Park et al. [35] & Stress radiographs in dorsiflexion/external rotation were most predictive \\
McConnell et al. [29] & Soft-tissue indicators are not accurate predictors of instability \\
Gill et al. [18] & Manual is equivalent to gravity-stress radiographs \\
Egol et al. [16] & $\begin{array}{l}\text { Medial tenderness, swelling, and ecchymosis were not sensitive } \\
\text { in predicting instability }\end{array}$ \\
Michelson et al. [32] & $\begin{array}{c}\text { Gravity-stress radiographs were found to reproducibly document } \\
\text { destabilizing deltoid ligament damage }\end{array}$ \\
Schuberth et al. [46] & Deltoid ligament integrity cannot be reliably predicted by the MCS \\
on injury radiographs and by LH classification
\end{tabular}

\section{Physical examination}

DeAngelis et al. [12] found a sensitivity of 57\%, a specificity of $59 \%$, a positive predictive value of $50 \%$, a negative predictive value of $66 \%$, and an accuracy of $42 \%$ for medial tenderness as a measure of deep deltoid ligament incompetence. Egol et al. [16] reported on the sensitivity and specificity for medial tenderness, swelling, and ecchymosis alone and in combination. They found a range of sensitivities from 20 to $56 \%$ and specificities from 71 to $97 \%$. McConell et al. [29] reported a $56 \%$ positive predictive value for severe tenderness as a predictor of a rupture. 
Severe soft-tissue swelling was seen in 24,35 , and $56 \%$ for SER II, stress-positive SER IV, and displaced SER IV fractures, respectively. Severe medial ecchymosis was seen in 5, 6, and 19\% for SER II, stress-positive SER IV, and displaced SER IV fractures, respectively.

Injury radiographic view

Schuberth et al. [46] showed that with arthroscopic visualization of the deep deltoid ligament as a golden standard, an MCS of $3 \mathrm{~mm}$ on the injury radiograph had a false-positive rate for deltoid rupture of $88.5 \%$. At an MCS of $4 \mathrm{~mm}$, the false-positive rate was $53.6 \%$. At an $\mathrm{MCS} \geq 5 \mathrm{~mm}$, the false-positive rate for deltoid rupture diminished to $26.9 \%$. With an MCS $\geq 6 \mathrm{~mm}$, the false-positive rate for deltoid rupture was only $7.7 \%$.

\section{Radiographic stress view}

DeAngelis et al. [12], Egol et al. [16], McConnell et al. [29] used a manual external rotation stress radiograph as a golden standard to compare with the physical examination.

In the radiographic analysis of McConnell et al. [29] there were significant differences between the displaced SE4 fractures and the SE2 and stress (+) SE4 fractures with regard to the MCS and fibular displacement $(P<0.0001)$. On the stress radiographs, the MCS averaged $3.63 \mathrm{~mm}$ for the SE2 fractures and $5.69 \mathrm{~mm}$ for the stress (+) SE4 fractures $(P<0.0001)$.

Gill et al. [18] compared the gravity (Fig. 1) with the manual-stress radiographs. In the SER II group, the average MCS was 4.15 and $4.26 \mathrm{~mm}$ on the manual and gravity- stress radiographs, respectively $(P=0.50)$. In the SER IV group, the average MCS was 5.21 and $5.00 \mathrm{~mm}$ on the manual and gravity-stress radiographs, respectively $(P=0.69)$. There were significant differences between the SER II group and the SER IV group with regard to the MCS on both the manual and gravity-stress radiographs $(P<0.02$ and $P<0.05$, respectively).

Michelson et al. [32] showed with a gravity-stress radiograph that regardless of the fibular status, releasing the superficial deltoid did not alter talar shift or talar tilt. The combination of deep and superficial deltoid release resulted in significantly increased talar shift $(P=0.003)$ and tilt $(P=0.0001)$. They found the gravity-stress view to be $100 \%$ sensitive and $100 \%$ specific for identifying ankles with deep deltoid ligament transection [32].

Park et al. [35] showed that measurement of an $\mathrm{MCS} \geq 5 \mathrm{~mm}$ on stress radiographs taken in dorsiflexionexternal rotation yielded a sensitivity of $100 \%$ (95\% CI, $61-$ $100 \%$ ), specificity of $100 \%$ (95\% CI, 89-100\%), and positive and negative predictive values of $100 \%$. As expected, larger medial clear space thresholds usually resulted in higher specificity but lower sensitivity. When measuring an absolute width to predict deep deltoid ligament status, radiographs taken with external rotational stress applied yielded the highest combination of sensitivity, specificity, positive predictive value, and negative predictive value in predicting deep deltoid ligament transection. Furthermore, of the three positions of ankle flexion stressed in external rotation, dorsiflexion was most predictive of deep deltoid ligament transection in terms of these statistical parameters.

Schock et al. [45] measured a mean MCS of $6.09 \mathrm{~mm}$ (4.4-8.1) on gravity-stress radiographs, and $5.81 \mathrm{~mm}$

Fig. 1 Gravity-stress radiograph

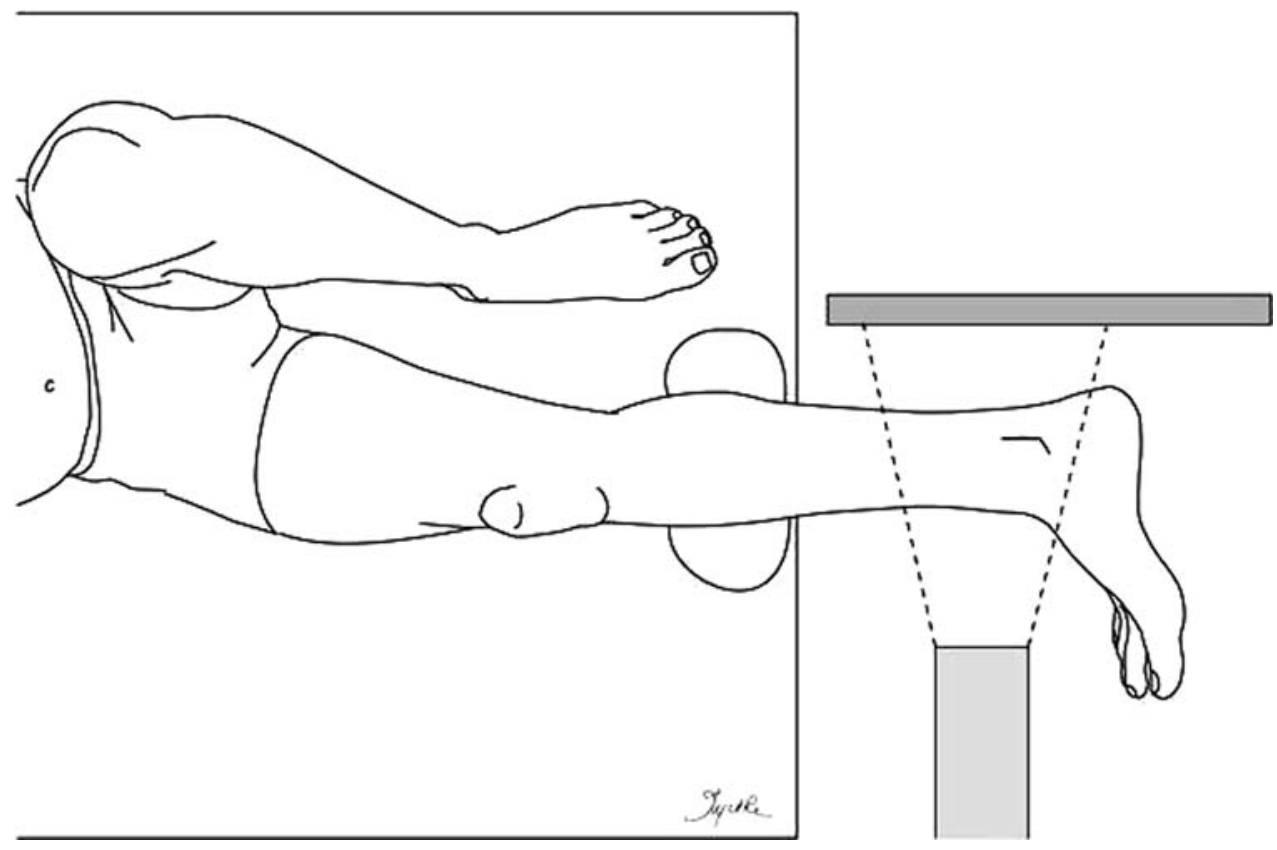


(4.0-8.2) on manual-stress examination $(P=0.63)$. Thirteen $(45 \%)$ were stress-negative with a mean MCS measuring $3.91 \mathrm{~mm}(3.3-5.1)$ on gravity-stress, and $3.61 \mathrm{~mm}$ (2.6-4.5) on manual-stress examination $(P=0.39)$. There was a statistically significant difference in the mean values of stress-positive and stress-negative examinations in both the examinations of gravity-stress and manual-stress ( $P<0.0001$ and $P=0.0003$, respectively). The mean increase in pain VAS from pretesting to gravity-stress was $0.64(0-6)$ and from pretesting to manual-stress testing 2.96 (3-9). The change in pain VAS score from pretesting to gravity-stress testing when compared to that of pretesting to manual-stress testing was statistically significant $(P<0.0001)$.

\section{Lauge-Hansen classification}

After evaluation of the 40 ankle fractures according to the Lauge-Hansen classification, the integrity of the deltoid ligament was opposite to that of the expected findings in three fractures [46].

\section{Ultrasound}

No studies were found using ultrasound in evaluating deltoid ligament integrity in patients with SER ankle fractures.

\section{MRI}

The value of MRI in evaluating deltoid ligament integrity could not be determined on the basis of this search of the literature. In a preliminary report, Koval et al. [24] observed that 19 of 21 patients $(90 \%)$ who had a positive manual-stress radiograph (MCS $>5 \mathrm{~mm}$ ) had evidence of only a partially torn deep deltoid ligament on MRI.

\section{Arthroscopy}

Schuberth et al. [46] used this measurement as a golden standard to retrospectively compare with the MCS on the injury radiograph and to compare with the Lauge-Hansen classification. The value of arthroscopy in evaluating deltoid ligament integrity could not be determined on the basis of this search of the literature.

\section{Discussion}

In high fibular fractures (PER [26, 34, 58] or Weber C [10, 53]) there is an obvious indication for surgery to maintain the congruency of the ankle mortise. In lower fibular fractures (SER [26, 34, 58] or Weber B [10, 53]) there is an indication for surgery when the deltoid ligament is ruptured even when there is no tibiotalar dislocation on the trauma radiographs [30, 31]. The above is mentioned because the lateral (lateral malleolus and lateral ligaments) or the medial side (medial malleolus or deltoid ligament) of the ankle has to be stable to avoid tibiotalar dislocation. A reliable evaluation of the deltoid ligament integrity is essential in the evaluation if there is an indication for surgery in the not or little displaced SER or Weber B fractures.

Orthopedic surgeons most often rely on clinical signs such as ecchymosis, swelling, and tenderness to evaluate integrity of the medial structures because they are quick, easy, and inexpensive [2, 7, 27, 36, 37, 41]. An American Academy of Orthopaedic Surgeons review literature supports the use of medial tenderness as a predictor of deep deltoid disruption in SER-type ankle fractures [5]. Recent reports have questioned the reliability of these clinical findings [1, 29]. Current literature supports the concept that clinical features of the injured ankle are inadequate predictors of the stability of the ankle joint [12, 16, 29]. Especially a high specificity is important to avoid that SER IV ankle fractures are refrained from open reduction and internal fixation. While it is likely that the patient has a soft-tissue injury if these symptoms are present, it may not be a complete deep deltoid injury and the deltoid ligament may not be incompetent. The superficial deltoid ligament, taking its origin from the anterior colliculus, does not contribute to medial stability of the ankle and may be injured by means of a rotational mechanism [29, 31, 39].

Because the initial injury radiographs of an ankle with an isolated distal fibular fracture may be inconclusive, a stress radiograph is recommended to determine the medial clear space [16, 29]. The integrity of the deep deltoid ligament can be indirectly evaluated by the medial clear space on these stress radiographs and is measured from the superiormedial aspect of the talus to the superior-medial corner of the plafond on a mortise radiograph. External rotation stress radiographs, as described by Pankovich, are considered the gold standard, but this test has some shortcomings and has never been validated [19, 29, 36-39, 52]. Tornetta stated that these tests are the gold standard of subluxation, an indirect measurement of deltoid injury or deltoid insufficiency. The amount of medial clear space widening indicative of a positive external rotation stress or gravity-stress test has been somewhat variable in the literature $[8,12,16,18,19$, 21, 23, 28, 29, 32, 35, 40, 46]. Normal values reported in the literature have varied from 1 to $5 \mathrm{~mm}[8,11,19,21$, 28]. A medial clear space of $\geq 4 \mathrm{~mm}$, with that value being at least $1 \mathrm{~mm}$ greater than the superior tibiotalar space is a value that is accepted to represent an unstable ankle fracture $[2,16,18,20,29,30,40]$. A recent cadaver study examining the position of the ankle at the time of stress radiography demonstrated that a medial clear space of $\geq 5 \mathrm{~mm}$ was a reliable predictor of deltoid ligament 
incompetence [35]. Michelson et al. [32] found that an increase in medial clear space of $2 \mathrm{~mm}$ from its baseline value occurred only after complete disruption of the deep deltoid ligament. Regardless of the fibular status, transection of the superficial deltoid ligament alone did not cause medial clear space widening [32].

The direction of rotational stress applied to the foot had a greater effect on medial clear space in predicting deep deltoid ligament status than did the position of ankle flexion [35].

Ankle stress radiographs taken in dorsiflexion with external rotation were most predictive of deep deltoid ligament disruption after distal fibular fracture [35]. Patients may experience pain during an ankle stress test, which would increase the role of active muscle forces in ankle dynamics, and this would limit the amount of rotation that one could apply to the injured ankle. The amount of applied force necessary when performing an external rotation stress radiograph is not well defined; Xenos recommended $5 \mathrm{Nm}$, McConnell and Park recommended $8 \mathrm{lb}$, and Tornetta used $20 \mathrm{lb}$ [29, 32, 52, 55]. External rotation stress radiographs are only well tolerated with use of narcotics or anesthesia [12]. There was no significant difference between the gravity and the manual-stress radiograph with regard to mean medial clear space or talar shift measured in association with either fracture pattern [18]. The VAS score for examinations of manual-stress indicated that patients perceived more discomfort than with gravity testing [45]. The main limitation of the gravity-stress radiograph is the inability to control dorsiflexion and plantar flexion [18]. This technique involves less radiation exposure to the physician and can be performed by a radiology technician [18].

Arthroscopy has been used in the past to assess cartilage lesions and ligamentous damage in acute ankle trauma [14, 15, 22]. Arthroscopic evaluation of the deep deltoid ligament in patients with a suspected rupture of the deltoid ligament is not a practical diagnostic modality. Schuberth et al. [46] compared deep deltoid ligament integrity with corresponding medial clear space measurements in the clinical setting. They concluded that displaced lateral malleolar fractures in patients with medial ankle tenderness, but without overt widening of the medial clear space on injury radiographs require careful attention because the integrity cannot be reliably predicted by injury radiographs [46]. Although use of the Lauge-Hansen classification accurately determined most fracture patterns, it has been shown that the system cannot be applied consistently among users with only poor-to-fair inter-observer reliability [30, 34, 44, 57]. The problem of inconsistent application of the Lauge-Hansen scheme is compounded by fracture patterns that escape this classification system altogether $[17,46]$. Some fractures considered stable by the Lauge-
Hansen classification may require careful scrutiny to rule out deep deltoid injury [46]. These findings are in agreement with the study of Gardner et al. [17] that the LaugeHansen system should only be used only as a guide in the diagnosis and management of ankle fractures and not solely relied upon for treatment decisions. MRI could be helpful in determining deltoid ligament integrity and be useful in individual cases in which doubt about joint stability and soft-tissue integrity exists $[17,47]$. In a preliminary report, Koval et al. [24] observed that 19 of 21 patients (90\%) who had a positive manual-stress radiograph (MCS $>5 \mathrm{~mm}$ ) had evidence of partially torn deep deltoid ligament on MRI. These patients were treated nonoperatively, whereas two patients had MRI findings of a complete deep deltoid injury and underwent surgical treatment. With use of the MRI, they were able to identify and provide effective nonoperative care to 19 patients who otherwise might have undergone operative treatment after an isolated lateral malleolar fracture [24]. Medial clear space measurements on manual-stress radiographic testing did not correlate with deep deltoid rupture on MRI [24]. These conclusions should be interpreted with caution because of the incomplete follow-up and the short term follow-up [24]. Clearly there are limitations in its practicality because of cost and convenience.

Implications for future research

Future research especially on stress radiographs should focus on the comparison of the injured with the uninjured contralateral ankle. The applied force in the stress radiographs and the magnitude of the medial clear space should be determined. The physical examination should be performed within $24 \mathrm{~h}$ and repeated within 5 days because in some ankles the ecchymosis develops later. The contribution of the superficial deltoid ligament to talar stability in the ankle mortise should be determined. The value of MRI and ultrasound investigation in determining deltoid ligament integrity should be confirmed and a subset of patients who will benefit from an MRI in evaluating deltoid ligament integrity should be identified. Future trials should be prospective and on larger sample sizes.

Implications for clinical practice

In Table 3, a flow chart for treatment of supination external rotation ankle fractures with suspected deltoid ligament rupture is formulated. Clinical features (swelling, ecchymosis and medial tenderness) of the injured ankle are less adequate predictors of the stability of the deltoid ligament. Initial injury radiographs of an ankle with an isolated distal fibular fracture and the Lauge-Hansen classification may be inconclusive to detect deltoid ligament rupture. Manual or 
Table 3 Flow chart for treatment of minimally displaced SER ankle fractures with suspected deltoid ligament rupture

Soft tissue signs of injury (swelling, ecchymosis, medial tenderness)

NO

Medial clear space $\geq 4 \mathrm{~mm}$ on injury radiograph

YES

Operative treatment
NO

Non-operative treatment
YES

Medial clear space $\geq 5 \mathrm{~mm}$ on injury radiograph

YES NO

Operative treatment Manual or gravity stress radiograph

Medial clear space $\geq 4 \mathrm{~mm} \quad$ Medial clear space $\leq 4 \mathrm{~mm}$

Operative treatment Non-operative treatment

with close follow-up or

MRI in selected cases.

Operative treatment: Open reduction and internal fixation of fibular fracture; there is no indication for suturing the deltoid ligament.

gravity external rotation stress radiographs are considered the current best available diagnostic in evaluation deltoid ligament insufficiency. The amount of medial clear space widening indicative of a positive external rotation stress test has been somewhat variable but all authors agree that a clear space of $\geq 5 \mathrm{~mm}$ is compatible with a rupture of the deep deltoid ligament. Understanding the normal radiographic relationship of the ankle mortise to compare the medial clear space with the superior clear space helps in the diagnosis of deltoid ligament injury. Adding an X-ray ruler would be helpful to determine the medial clear space. Achieving adequate external rotation of the foot, when obtaining stress radiographs, is more important than positioning the ankle in the appropriate degree of ankle flexion. The amount of applied force necessary when performing an external rotation stress radiograph is not well defined and mainly determined by the patient's pain level. The gravitystress has demonstrated to be as reliable as the manualstress radiograph. The indication for surgery should not be based on a combination of several parameters. If nonoperative treatment is chosen despite a positive stress radiograph, close follow-up is critical because subluxation of the ankle joint can early take place. MRI could be helpful in determining deltoid ligament integrity and be useful in individual cases in which doubt about joint stability and soft-tissue integrity exists.

Acknowledgments The authors did not receive any outside funding or grants in support of their research for or preparation of this work. Neither they nor any member of their immediate families received payments or other benefits or a commitment or agreement to provide such benefits from a commercial entity. No commercial entity paid or directed, or agreed to pay or direct, any benefits to any research fund, foundation, division, center, clinical practice, or other charitable or non-profit organization with which the authors, or a member of their immediate families, are affiliated or associated.
Open Access This article is distributed under the terms of the Creative Commons Attribution Noncommercial License which permits any noncommercial use, distribution, and reproduction in any medium, provided the original author(s) and source are credited.

\section{References}

1. Amirtharajah M, Egol K, Tejwani NC et al (2004) Ankle stress test for predicting the need for surgical fixation of isolated fibular fractures. J Bone Joint Surg Am 86:2393-2398

2. Baird RA, Jackson ST (1987) Fractures of the distal part of the fibula with associated disruption of the deltoid ligament Treatment without repair of the deltoid ligament. J Bone Joint Surg Am 69:1346-1352

3. Bauer M, Bergstom B, Hemborg A et al (1985) Malleolar fractures: nonoperative versus operative treatment: a controlled study. Clin Orthop Relat Res 199:17-27

4. Bauer M, Johnson K, Nilsson B et al (1985) Thirty-year follow-up of ankle fractures. Acta Orthop Scand 56:103-106

5. Baumhauer JF, Geppert MJ, Michelson JD et al (2002) Ankle and foot: trauma. In: Koval K (ed) Orthopaedic knowledge update 7. American Academy of Orthopaedic Surgeons, Rosemont, p 548

6. Boden SD, Labropaulos PA, McCowin P et al (1989) Mechanical considerations for the syndesmosis screw. J Bone Joint Surg 71(10): 1548

7. Brink O, Staunstrup H, Sommer J et al (1996) Stable lateral malleolar fractures treated with air cast ankle brace and Donjoy R.O.M.-Walker brace: a prospective randomized study. Foot Ankle Int 17:679-684

8. Carr JB, Trafton P (1998) Malleolar and soft tissue injuries of the ankle. In: Browner B, Jupiter J et al. (eds) Skeletal trauma. Saunders, Philadelphia, p 2357

9. Cedell CA (1985) Is closed treatment of ankle fractures advisable? Acta Orthop Scand 56:101-102

10. Danis R (1949) Les fractures malleolaires. In: Danis R (ed) Theorie et Pratique de l'Osteosynthese, pp 133-165

11. DeAngelis JP, Anderson R, DeAngelis NA (2007) Understanding the superior clear space in the adult ankle. Foot Ankle Int 28(4):490-493. doi:10.3113/FAI.2007.0490

12. DeAngelis NA, Eskander MS, French BG (2007) Does medial tenderness predict deep deltoid ligament incompetence in 
supination-external rotation type ankle fractures? J Orthop Trauma 21(4):244-247. doi:10.1097/BOT.0b013e3180413835

13. DeSouza CJ, Gustilo RB, Meyer TJ (1985) Results of operative treatment of displaced external rotation-abduction fractures of the ankle. J Bone Joint Surg 67(7):1066-1074

14. van Dijk CN, Bossuyt PM, Marti RK (1996) Medial ankle pain after lateral ligament rupture. J Bone Joint Surg Br 78(4):562-567

15. van Dijk CN, Verhagen RA, Tol JL (1997) Arthroscopy for problems after ankle fracture. J Bone Joint Surg Br 79(2):280-284. doi:10.1302/0301-620X.79B2.7153

16. Egol KA, Amirtharajah M, Tejwani NC, Capla EL, Koval KJ (2004) Ankle stress test for predicting the need for surgical fixation of isolated fibular fractures. J Bone Joint Surg 86A(11):2393-2398

17. Gardner MJ, Demetrakopoulos D, Briggs SM, Helfet DL, Lorich DG (2006) The ability of the Lauge-Hansen classification to predict ligament injury and mechanism in ankle fractures: an MRI study. J Orthop Trauma 20(4):267-272. doi:10.1097/00005131200604000-00006

18. Gill JB, Risko T, Raducan V, Grimes JS, Schutt RC Jr (2007) Comparison of manual and gravity stress radiographs for the evaluation of supination-external rotation fibular fractures. J Bone Joint Surg 89(5):994-999. doi:10.2106/JBJS.F.01002

19. Harper MC (1987) Deltoid ligament: an anatomic evaluation of function. Foot Ankle 8:19-22

20. Harper MC (1988) The deltoid ligament. An evaluation of need for surgical repair. Clin Orthop Relat Res 226:156-168

21. Harper MC (1995) The short oblique fracture of the distal fibula without medial injury: an assessment of displacement. Foot Ankle Int 16:181-185

22. Hintermann B, Regazzoni P, Lampert C, Stutz G, Gachter A (2000) Arthroscopic findings in acute fractures of the ankle. J Bone Joint Surg 82B:345-351. doi:10.1302/0301-620X.82B3. 10064

23. Joy G, Patzakis MJ, Harvey JP Jr (1974) Precise evaluation of the reduction of severe ankle fractures. J Bone Joint Surg 56:979-993

24. Koval KJ, Egol KA, Cheung Y, Goodwin DW, Spratt KF (2007) Does a positive ankle stress test indicate the need for operative treatment after lateral malleolus fracture? A preliminary report. J Orthop Trauma 21(7):449-455. doi:10.1097/BOT.0b013e 31812eed25

25. Kristensen KD, Hansen T (1985) Closed treatment of ankle fractures: stage II fractures followed for twenty years. Acta Orthop Scand 56:107-109

26. Lauge-Hansen N (1954) Fractures of the ankle III: genetic roentgenologic diagnosis of fractures of the ankle. Am J Roentgenol Radium Ther Nucl Med 71:456-471

27. Malka J, Taillard W (1969) Results of non-operative and operative treatment of fractures of the ankle. Clin Orthop Relat Res 67:159168. doi:10.1097/00003086-196911000-00024

28. Marsh JL, Salzman CL (2001) Ankle fractures. In: Bucholz R, Heckman JD (eds) Fractures in adults. Lippincott, Philadelphia, p 2003

29. McConnell T, Creevy W, Tornetta P 3rd (2004) Stress examination of supination external rotation-type fibular fractures. J Bone Joint Surg 86A(10):2171-2178

30. Michelson JD (1995) Fractures about the ankle. J Bone Joint Surg 77:142-152

31. Michelsen JD, Ahn UM, Helgemo SL (1996) Motion of the ankle in a simulated supination-external rotation fracture model. J Bone Joint Surg 78:1024-1031

32. Michelson JD, Varner KE, Checcone M (2001) Diagnosing deltoid injury in ankle fractures: the gravity stress view. Clin Orthop Relat Res 387:178-182. doi:10.1097/00003086-20010600000024
33. Mont MA, Sedlin ED, Weiner LS, Miller AR (1992) Postoperative radiographs as predictors of clinical outcome in unstable ankle fractures. J Orthop Trauma 6:352-357. doi:10.1097/00005131199209000-00014

34. Nielsen JO, Dons-Jensen H, Sorensonn HT (1990) Lauge-Hansen classification of malleolar fractures. An assessment of the reproducibility in 118 cases. Acta Orthop Scand 61:385-387

35. Park SS, Kubiak EN, Egol KA, Kummer F, Koval KJ (2006) Stress radiographs after ankle fracture: the effect of ankle position and deltoid ligament status on medial clear space measurements. J Orthop Trauma 20(1):11-18. doi:10.1097/01.bot.0000189591. 40267.09

36. Pankovich AM (1979) Fractures of the fibula at the distal tibiofibular syndesmosis. Clin Orthop Relat Res 143:138-147

37. Pankovich AM, Shivaram MS (1979) Anatomic basis of the variability in injuries of the medial malleolus and the deltoid ligament I: anatomical studies and II: clinical studies. Acta Orthop Scand 50:217-236

38. Pankovich AM (1991) Trauma to the ankle. In: Jahss MH (ed) Disorders of the foot and ankle: medical and surgical management, 2nd edn. Saunders, Philadelphia, pp 2361-2414

39. Pankovich AM (2002) Acute indirect ankle injuries in the adult. J Orthop Trauma 16:58-68. doi:10.1097/00005131-20020100000015

40. Phillips WA, Schwartz HS, Keller CS, Woodward HR, Rudd WS, Spiegel PG et al (1985) A prospective, randomized study of the management of severe ankle fractures. J Bone Joint Surg 67:67-78

41. Port A, McVie J, Naylor G et al (1996) Comparison of two conservative methods of treating an isolated fracture of the lateral malleolus. J Bone Joint Surg 78(4):568-572

42. Rasmussen O, Kromann-Andersen C, Boe S (1983) Deltoid ligament Functional analysis of the medial collateral ligamentous apparatus of the ankle joint. Acta Orthop Scand 54:36-44

43. Rasmussen O (1985) Stability of the ankle joint Analysis of the function and traumatology of the ankle ligaments. Acta Orthop Scand Suppl 211:1-75

44. Rasmussen S, Madsen PV, Bennicke K (1993) Observer variation in the Lauge-Hansen classification of ankle fractures Precision improved by instruction. Acta Orthop Scand 64:693-694

45. Schock HJ, Pinzur M, Manion L, Stover M (2007) The use of gravity or manual-stress radiographs in the assessment of supinationexternal rotation fractures of the ankle. J Bone Joint Surg Br 89B(8):1055-1059. doi:10.1302/0301-620X.89B8.19134

46. Schuberth JM, Collman DR, Rush SM, Ford LA (2004) Deltoid ligament integrity in lateral malleolar fractures: a comparative analysis of arthroscopic and radiographic assessments. J Foot Ankle Surg 43(1):20-29. doi:10.1053/j.jfas.2003.11.005

47. Sheth DS, Ambrose CG (2005) Stress test for predicting the need for surgical fixation of fibular fractures. J Bone Joint Surg 87(5):1165 author reply 1165

48. Snedden MH, Shea JP (2001) Diastasis with low distal fibula fractures: an anatomic rationale. Clin Orthop Relat Res 382:197-205. doi:10.1097/00003086-200101000-00027

49. Solari J, Benjamin J, Wilson J et al (1991) Ankle mortise stability in Weber C fractures: indications for syndesmotic fixation. J Orthop Trauma 5(2):190-195. doi:10.1097/00005131-19910502000012

50. Stroup DF, Berlin JA, Morton SC, Olkin I, Williamson GD, Rennie D et al (2000) Meta-analysis of observational studies in epidemiology: a proposal for reporting. Meta-analysis of observational studies in epidemiology (MOOSE) group. JAMA 283:2008-2012. doi:10.1001/jama.283.15.2008

51. Thomsen NOB, Overgaard S, Olsen LH, Hansen H, Nielsen ST (1991) Observer variation in the radiographic classification of ankle fractures. J Bone Joint Surg 73(4):676-678 
52. Tornetta P 3rd (2000) Competence of the deltoid ligament in bimalleolar ankle fractures after medial malleolar fixation. J Bone Joint Surg 82(6):843-848

53. Weber BG (1972) Die Verletzungen des Oberen Sprunggellenkes. Hans Huber, Bern

54. Wei SY, Okereke E, Winiarsky R et al (1999) Non-operative treatment of displaced bimalleolar and trimalleolar ankle fractures: A twenty-year follow-up. Foot Ankle Int 20:404-407

55. Xenos JS, Hopkinson WJ, Mulligan ME et al (1995) The tibiofibular syndesmosis. J Bone Joint Surg 77(6):847-857
56. Yablon IG, Heller FG, Shouse L (1976) The key role of the lateral malleolus in the displaced fracture of the ankle. J Bone Joint Surg 59(2):169-173

57. Yde J (1980) The Lauge Hansen classification of malleolar fractures. Acta Orthop Scand 51:181-192

58. Yde J, Kristensen KD (1980) Ankle fractures: supination-inversion fractures stage II: primary and late results of operative and non-operative treatment. Acta Orthop Scand 51:695-702 